\title{
MODEL PENDEKATAN PEMBELAJARAN SEJARAH DARI ISUS-ISU KONTROVERSIAL, SEJARAH-KOMPARATIF KE ANALISIS TEKSTUAL
}

\author{
Helius Sjamsuddin *)
}

\begin{abstract}
Abstrak
Pengajaran sejarah umumnya masih dalam hafalan faktual saja. Menurut jenjang usia, para siswa juga diperkenankan secara sederhana cara kerja (metode) sejarawan mengumpulkan materi sejarah sampai pada penulisannya (historiografi).. Munculnya isu-isu kontroversial ada hubungannya dengan masalah obyektivitas dan / subyektivitas sejarah. Sejarawan yang baik sepakat menulis karya sejarah yang tidak memihak dan tidak bersifat pribadi. Pada kenyataannya setiap mata pelajaran (subject matter) atau disiplin memiliki masalah kontroversial yang tidak terpecahkan. Meskipun sebuah topik secara politik kontroversial tidak berarti sekolah atau guru secara individual netral. Para guru telah menggunakan pendekatan tertentu dalam mengajarkan isu-isu kontroversial.
\end{abstract}

Kata Kunci : Pendekatan Pembelajaran, Isu-isu Kontroversial, Sejarah Komparatif

\section{Pengantar}

Guru-guru Sejarah dari berbagai jenjang pendidikan acapkali mengeluh karena banyak siswa dari kelas-kelas sejarah mereka kurang kalau tidak dapat dikatakan tertarik kepada pengajaran (teaching) dan pembelajaran (learning) mata pelajaran (subject-matter) sejarah. Alasan kalsik, biasanya sejarah itu merupakan hafalan yang membosankan, "cerita" tentang orang-orang ternama, peristiwa-peristiwa, tempat-tempat, waktu lampau (past) yang sama sekali tidak ada hubungannya dengan mereka. Berbagai metode dan pendekatan yang diajarkan atau latihan seperti Penelitian Tindakan Kelas (PTK, ClassroomAktion Research) kepada guru-guru sejarah agar mempelajari mata pelajaran yang mereka berikan menarik dan oleh karena itu dapat memberikan motivasi kepada siswa untuk belajar dan mengapresiasi lebih lanjut apa yang mereka peroleh dan pada gilirannya memberikan hasil (produk) dan manfaat bagi peserta didik. Namun dari hasil-hasil penelitian belum banyak memberikan manfaat sehingga kita tidak jemu-jemu mencari cara-cara berdasarkan perkembangan teori-teori belajar agar pengajaran dan pembelajaran sejarah selain menarik juga efektif. Teori-teori belajar dari 
sampai kita memasuki abad ke-21 sekarang, sejak dari Behaviorisme (pembelajaran terjadi ketika perilaku atau perubahan perilaku diperoleh sebagai hasil dari jawaban individual terhadap stimulasi/ rangsangan). Kognitivisme (pembelajaran adalah suatu perubahan dalam pengetahuan yang disimpan dalam ingatan), sampai kepada kontruktivisme (pembelajaran adalah suatu proses dimana individuindividu mengkontruksikan ide-ide atau konsep-konsep baru berdasarkan atas pengetahuan dan/atau pengalaman yang telah ada sebenarnya/sebelumnya) sekarang, (http://www.myecoach.com/ idtimelitine/learningtheory.html. 08-02-2004) dalam prakteknya belum banyak pembuahan hasil untuk hampir semua disiplin ilmu, termasuk sejarah. Pertemuan kita ini juga adalah dalam rangka itu semua.

\section{Apa itu belajar sejarah ?}

Brian Garvey dan Mary Krug menulis bahwa paling tidak yang disebut belajar sejarah (studying history) itu :

1. Memperoleh pengetahuan fakta-fakta sejarah

2. Memperoleh pemahaman atau apresiasi peristiwa-peristiwa atau periode-periode atau orang-orang dari masa lalu.

3. Mendapatkan kemampuan mengevaluasi dan mengkritik karya-karya sejarah.

4. Belajar teknik-teknik penelitian sejarah.

5. Belajar bagaimana menulis sejarah. (Garvey dan Krug, 1977:2).

Umumnya kita mengajarkan sejarah masih dalam tahap pertama (kognitif) hafalan faktual saja. Kita masih menanyakan pada siswa-siswa kita pertanyaan-pertanya- abad ke-20 yang selalu

an dasar seperti apa, siapa, kapan, dimana, dan paling jauh bagaimana (proses terjadinya). Memang kita tidak salah, hanya mengajukan pertanyaan kritis seperti mengapa yang membuat siswa terpaksa harus "memutar otak" melakukan inkuri (inqury) mencari sebab peristiwa baik yang terpendam maupun yang terbuka.

Sebenarnya belajar sejarah tidak berhenti disitu saja, melainkan siswa-siswa diharapkan dapat mengapresiasi (afaktif) apa yang telah dipelajarinya tentang orangorang, masa-masa dan peristiwa-peristiwa tertentu dari masa lalu. Siswa harus mencari makna (meaning) dan belajar suatu kejadian, apakah itu baik buruk buruk. Tahap berikutnya di bawah bimbingan guru tentu saja siswa-siswa perlu mengevaluasi dan mengkritik buku-buku test atau teks-teks sejarah (sebagai sumber pertama). Kemudian menurut jenjang usia siswa-siswa juga diperkenankan secara sederhana caracara kerja (metode) sejarawan mengumpulkan materi sejarah sampai pada penulisannya (historiografi), tentu saja untuk para siswa mereka belajar menulis dengan cara menyusun laporan-laporan sederhana tentang apa yang telah mereka cari dan kumpulkan. Untuk tahap terakhir ke-4 dan ke-5 sebenarnya kita telah mengajarkan kepada siswa-siswa "struktur" ilmu sejarah dengan cara sederhana, mudah, dan menarik.

\section{Model-model pendekatan}

\section{1) Isu-isu kontroversial (Contro-versial Issues)}

A. Masalah Objekvitas dan/atau
Subjektivitas Sejarah
Sebenarnya munculnya isu-isu kontroversial ada hubungannya dengan masalah obyektivitas dan/ subyekvitas 
sejarah yang masih merupakan debat lama yang tidak pernah selasai, paling tidak seperti yang direfleksikan dalam filsafat sejarah. Pertanyannya apakah sejarah dapat objektif? Sebenarnya bukan hanya sejarah saja tetapi juga disiplin-disiplin kognitif lain tidak dapat objektif yang dimaksud dengan kata "obyektif" itu tuntutan yang sulit atau mustahil dipenuhi seperti :

a. Kebenaran mutlak

b. Sesuai dengan kenyataan, termasuk juga yang tersembunyikan.

c. Netralitas mutlak, tidak memihak, dan tidak terikat.

d. Kondisi kondisi yang harus lengkap untuk peristiwa atau menuntuk penempatan seluruh peristiwa kedalam hukum-hukum yang berlaku umum. (Conkin dan Stromberg, 1971:85,197).

Sejarah sebagaimana yang dipenuhi oleh para sejarawan bukanlah masalalu melainkan catatan (record) daningatan (memory) mengenal masa lalu. Oleh sebab itu jika kita tidak ada catatan atau ingatan tidak ada sejarah. Sebagai catatan atau ingatan, tentu ada orang yang mencatat atau mengingat dan sebagai manusia ia (mereka) mempunyai pandangan-pandangan, mempunyai prasangka-prasangka yang memasuki catatan atau ingatan itu dan memberi warna tertentu kepadanya yang disebut memihak (bias). (Gee, 1950; 41-42, Dance,1960;9) dari sini saja si pencatat atau si pengingat (untuk tradisi lisan) sudah "subjektif". Laporan-laporan para pejabat Belanda, baik berupa etnografi dari kelompok-kelompok etnis di Indonesia ataupun mengenai perlawanan-perlawanan terhadap Belanda sebelum abad ke-20, misal, telah diwarnai dengan prasangka dan pemihakan mereka. laporan inilah yang menjadi sember-sumber pertama penulisan sejarah selai sumber-sumber pribumi lainnya. Ketika sejarawan Belanda menghasilkan karya-karya sejarah Indonesia sejarawan Indonesia sendiri juga menghasilkan tulisan sejarah yang bersebrangan dengan mereka.

Menurut Walsh (1960; 100-108) paling tidak ada empat kemungkinan yang menyebabkan tidak ada kesepakatan di antara sejarawan yang mempunyai konsekwensi kepada masalah subjektivitas dan objektivitas sejarah ini.

a. Pemihakan Pribadi (personal bias).

Persoalan suka dan tidak suka pribadi terhadap individual-individual atau golongan dari seseorang. Ada sejarawan seperti Carlyle mengagumi orang-orang besar. Carlyle menulis tentang cita-cita dan tindakan-tindakan dari perlawanan sebagai penentu jalannya sejarah pada waktunya. Sebaliknya Wells betapa tidak jujur atau jahat, misalnya, dari para pelaku sejarawan yang terutama tokoh-tokoh militer, tetapi karena pemihakan yang semacam ini karyakarya mereka dicap sebagai"sejarah yang buruk". Pada contoh lain, karya-karya biografi, memoir, atau otobiografi, mempunyai peluang besar adanya bias pribadi ini.

b. Prasangka Kelompok (group prejudice).

Di sini menyangkut keang-gotaan sejarawan dalam suatu kelompok apakah itu bagus, ras, kelompok sosial, atau agama tertentu. Sejarawan berkulit putih, misalnya, menulis sejarah dengan sikap angkuh dan menganggap diri lebih beradap dari pada bangsa-bangsa kulit berwarna yang pernah mereka taklukkan atau jajah. Pandangan yang Eropa Sentris atau Belanda sentris dalam sejarah Indonesia dahulu adalah salah satu contoh. Mengenai sebab-sebab Perang Dunia I dan Perang Dunia II, para sejarawan dari masing-masing pihak yang berperang kemudian menulis dan saling menyalahkan karena mereka berdiri dan melihat dari sudut pandang bangsanya. Mengenai Perang Dunia I, misalnya Jerman menulis White Book (3 Agustus 1914), Gray 
Book (6 Agustus 1914), Perancis Yellow Book (Desember 1914), Austria Red Book (Februari 1914). (Clogh, et.al., ed. 1970: 293; Cantor dan Berner,ed. 1971:213259;421-489).

c. Teori-teori yang berlawanan tentang penafsiran sejarah (conflicting theories of historical interpretation)

Sejarawan Marxis, misalnya, akan menulis berdasarkan teori determinisme ekonomi dalam menafsirkan faktor penyebab sejarah; bahwa ekonomilah satusatunya penggerak utama sejarah. Begitu pula para determinis lain yang akan menulis berdasarkan faktor atau tenaga tunggal ras, atau geografis.

d. Konflik-konflik filsafat yang mendasar (underlying philo-sopical conflicts)

Kaitanya dengan kepercayaan moral atau Weltanschauungen (pandangan hidup seseorang). Secara teoristis, seorang yang menganut filsafat hidup tertentu, paham, keper-cayaan, atau agama tertentu akan menulis sejarah berdasarkan pandangan ini.

Bagaimana juga para sejarawan yang baik sepakat untuk menulis karyakarya sejarah yang tidak memihak dan tidak bersifat pribadi. Semua karya sejarah yang ber-argumentasi dan kesimpulannya diputarbalik untuk tujuan-tujuan prasangka dan propaganda dianggap buruk. (Walsh, 1960:98).

\section{B. Apa itu isu-isu kontroversial?}

Pada kenyataan setiap mata pelajaran (subject matter) atau disiplin memiliki masalah-masalah kontroversial yang tidak terpecahkan. Para serawan misalnya, tidak sepakat mengenai tafsirantafsiran atas peristiwa-peristiwa dan tingkah laku seorang atau satu kelompok. Dalam geografi ada teori-teori dan model bagaimana yang berbeda tentang bagaimana kota-kota dikembangkan. Para ahli ekonomi bertengkar tentang sebab-sebab inflasi.
Dalam ilmu-ilmu alam ada pertentangan yang funda-mental tentang asal muasal angkasa, evolusi, penerapan praktis teoriteori dan temuan-temuan ilmiah, dampak kemajuan teknologi bagi kualitas hidup manusia. Menurut Stradling, mengajarkan berbagai mata pelajaran yang seolah-olah tidak ada kontroversi atau pertanyaan-pertanyaan terbuka tentang fakta dan menafsirkan, berarti salah mengarahkan siswa-siswa atau salah tafsir tentang hakekat dan perkembangan disiplin-disiplin ilmu dan metode-metode inkuiri. (Stradling, et.al. 1984:1)

\section{Hakekat kontroversi}

Stradling, et.al. mendefinisikan "isuisu kontroversial" (contro-versial issues) sebagai topik-topik dalam pembelajaran yang secara politik sensitif (politically sensitive) dimasukkan ke dalam kurikulum yang dapat menimbulkan gejolah kemarahan dalam masyarakat atau cara bagai-mana diajarkan. (Stradling, et.al. 1984:1)

Meskipun topik-topik itu secara politik kontroversial tidak berarti sekolah atau guru secara individual netral. Ketidaksepakatan mungkin karena evidensi-evidensi belum cukup sehingga masalah-masalah belum bisa dipecahkan suatu hal biasa dalam dunia akademik. Akan tetapi ada masalahmasalah yang tidak sanggaup mereka pecahkan meskipun sudah menampilkan misalnya, evidensi baru. Ketidak sepakatan dalam isu-isu inibiasanya menyangku masalah pertimbangan nilai (value judgement). Isu-isu besar dalam bidang politik, ekonomi dan sosial pada saat ini biasanya termasuk tipe ini. D. Fraser seperti yang dikutip oleh Stradling menyebutkan isuisu "yang oleh masyarakat tidak ditemukan solusinya dan yang diusulkan untuk hampir universal diakui", dan setiap cara-cara yang diusulkan untuk memecahanya menghadapi 
keberatan pada masyarakat lain dan menimbulkan protes. (Stradling, et.al. 1984:1). Kita masih menyaksikan sekarang kontraversi pro-kontra rancangan UndangUndang Anti-Pornografi dan Pornoaksi sekarang.

Masalah-masalah konflik nilai seringkali dihadapi guru sebagai masalah yang paling fundamental dalam pedagogi. Kita batasi penggunaan istilah isu kontroversial ini untuk maslah dan pertentangan yang dapat memecah belah masyarakat dan oleh sebab itu kelompok-kelompok penting dalam masyarakat menawarkan penjelasan-penjelasan konflik dan pemecahan-pemecahan berdasarkan atas nilai-nilai alternatif. Pertentangan itu mungkin tentang:

- Apa yang telah terjadi.

- Sebab-sebab dari situasi sekarang.

- Sasaran yang dikehendaki yang akan dituju.

- Cara tindakan yang akan di-tempuh.

- Dampak yang mungkin timbul dari tindakan itu. (Stradling, et.al. 1984:3)

Semakin kontemporer isu-isu itu semakin besar masalah yang dihadapi oleh guru, terutama karena hasilnya masih sulit untuk diramal-kan; kita tidak mempunyai rujukan melihat ke belakang (bindsight) mengenai pentingnya peristiwa-peristiwa terbaru itu; para siswa suka membawa ke kelas tafsiran-tafsiran, pengalaman-pengalaman dan prasangka-prasangka mereka, sumber-sumber pertama evidensi itu biasanya bias, tim tidak lengkap dan saling bertentangan bahkan sulit untuk menetapkan kriteria untuk menentukan apa yang bisa dan tidak bisa membentuk evidensi yang valid. Stradling, et.al. 1984:3)

\section{Mengapa mengajarkan isu-isu kontroversial?}

Guru-guru menggunakan pendekatan ini mengajarkan isu-isu kontroversial dalam pembelajaran mereka :

- Sebagai topik mungkin ada hubungan langsung dengan kehidupan siswa sendiri.

- Masalah-masalah besar dalam bidangbidang sosial, politik, ekonomi, dan moral pada masa kita sekarang dan akibatnya bagi aspek-aspek kehidupan yang perlu diketahui oleh para siswa.

- Masalah-masalah yang tersebar luas dan pentingnya bertahan lama yang kalau tidak diketahui akan ada jurang yang serius bagi pendidikan anak-anak.

- Tema-tema yang berhubungan dengan isu-isu yang berpusat pada hubungan antara gender, distribusi sumber-sumber langka dalam masyarakat, kerja, perang dan damai, hukum dan ketertiban, dll.

- Isu-isu itu menawarkan suatu fokus yang bermanfaat bagi siswa untuk mengembangkan keterampilan akademik dan kajian mereka (misalnya dalam membangun hipnotis, mengumpulkan temuan-temuan).

- Isu-isu menawarkan suatu konteks yang berguna untuk mempraktekkan ketrampilan-ketrampilan sosial dan kehidupan (misalnya, ketrampilan berkomunikasi dengan orang-orang lain, kerjasama dalam proyek-proyek dll).

- Karena isu-isu spesifik dapat membuktikan bermanfaat bagi studi-studi kasus untuk memahami teori, konsepkonsep dan generalisasi (misalnya konflik-konflik di tanah air untuk memahami teori-teori konflik politik, agama, etnis). Stradling, et.al. 1984:3-4)

Apa yang disebutkan oleh Stradling ini lebih sesuai untuk mahasiswa dari pada untuk siswa sekolah lanutan pertama dan atas. Disinilah peran guru-guru sejarah sebagai fasilitator untuk lebih menyeder- 
hanakan tingkat kesukaran isu-isu kontroversial itusesuai dengan perkembangan usia para siswa untuk dapat menangkap dan memahaminya.

\section{E. Strategi dan metode pengajaran}

Empat hal yang harus menjadi perhatian :

- Seimbang (balance). Kepada siswasiswa diberikan sebagai alternatif sudut pandang yang berbeda agar mereka mendapat gambaran yang relatif seimbang.

- Netralitas (netrality). Guru sedapat mungkin bersikap netral terhadap opini yang berbeda, yang berkembang dalam diskusi ataupun bias yang telah dibawa para siswa dari luar, meskipun pada hakekatnya guru-guru juga mempunyai pendirian sendiri.

- Komitmen (commitment). Guru-guru harus mempunyai tanggung jawab bahwa apa yang diajarkannya itu tidak harus bebas nilai (value free). Hanya ia harus mengingat sebagai pegangan utama lebih kepada nilai-nilai pendidikan dari pada substansi atau pemihakan.

- Indoktrinasi (indoctrination) selalu dihubungkan denga usaha-usaha mengajarkan itu benar atau umum dapat menerimanya tanpa evidensi/ bukti samasekali. Atas dasar ini guruguru yang menyebutkan jelas posisinya dalam isu-isu itu tidak perlu melakukan indoktrinasi :

a. Jika sudut pandang lain mendapat perlakuan yang jujur (fair) dan sama.

b. Jika guru hanya mencoba memperbaiki keseimbangan dengan menyatakan sudut pandang yang lain daripada sumber utama informasi dan opini yang diperoleh siswa dari luar, misalnya dari media masa.

c. Jika guru mendorong keberanian siswa yang menyatakan pandangan yang berbeda itu dengan pengamatan yang kritis.

d. Jika guru menyatakan pendapatnya sendiri yang berbeda dengan sikap dan asumsi-asumsi siswa sendiri. Stradling, et.al. 1984:5-10)

\section{2) Pendekatan Sejarah Komperatif (Historical Comparative Approach)}

Bermula pendekatan ini dari ahli sosiolagi yang melakukan penelitian $\mathrm{H}-\mathrm{C}$ (Historical Comparative) pada abad ke-19. Pada awalnya, karya-karya sejarah komparatif ini merupakan campuran (blend) sosiolagi, sejarah, ilmu politik dan ilmu ekonomi. (Neuman, 200:382). Komparasi adalah salah satu bentuk pendekatan sosiologi sejarah (historical Sosiology) yang lintas waktu (temporal) dan ruang (spasial0. Kita dapat membahas bangsa yang sama, atau bangsa-bangsa berbeda (sedikit atau banyak), kita dapat membahasnya listas masa (acroos time) dari dahulu sampai sekarang.

Sosiologi sejarah adalah kajian tentang masa lalu, mempelajari bagaimana masyarakat-masyarakat bekerja dan berubah. Penelitiannya merupakan "kolaborasi" antara sejarawan dan ahli sosiologi yang mempelajari "saling tembus" (mutual interpenetration) antar masalalu (past) dengan masa sekarang 9 present), peristiwa-peristiwa dan proses-proses, tindakan dan strukturasi. Mereka mencoba mengawinkan penjelasan konseptual, generalisasi komparatif, dan ekplorasi emperis (Smith, 1991: 30. Pendekatan semacam ini membahas banyak hal yang berhubungan dengan segala aspek kegiatan masyarakat manusia, berbagai isme seperti demokrasi, 
kapitalisme, pemerintah demokrasi dan nondemokrasi, nasionalisme, pembangunan bangsa (nation building), konflik-konflik politik, revolusi, perang, tumbuhnya kotakota, kewarganegaraan (citizenship) (Smith, 1991: ix; Neuman, 2000: 382-383).

Pendekatan ini masih langka kalau tidak dapat dikatakan belum digunakan dalam kelas-kelas sejarah oleh guru-guru sejarah kita. Tentu saja dituntut pengetahuan guru yang luas dan mendalam dalam berbagai fenomena sejarah dunia (dan Indonesia tentu saja). Model ini menggunakan perbandingan (compere) persamaan dan perbdaan (contrast). Misalnya kita membicarakan persamaan dan perbedaan denga revolusi-revolusi dibagian lain dunia seperti The Glorious Revolusion di Inggris (1688), Revolusi Amerika (1776), Revolusi Prancis (1789), Revolusi Rusia (1917) yang waktu dan tempatnya berbeda. Dengan cara membandingkan, diperoleh manfaat ganda selain melihat persamaan bahwa revolusi itu sebagai salah satu bentuk konflik dalam interaksi sosial (bisa antar negara, antar negara, atau intra bangsa sendiri), juga dapat melihat perbedaannya bahwa revolusi Inggris tidak sama dengan Amerika, tidak sama dengan Prancis, tidak sama dengan Rusia, tentu saja tidak sama dengan Indonesia. Bersamaan dengan itu kita dapat melihat keunikan dari revolusi Indonesia, umpamanya. Dengan demikian kita dapat mengapresiasi revolusi kita sendiri, melihat persamaan dan perbedaan denga revolusi bangsa-bangsa lain. Tentu saja kita dapat menggali apakah ada pengaruh dari revolusi-revolusi yang lain di Indonesia. Erosi bangsa kita sekarang dalam pembentukan nation building mungkin karena anak cucu kita tidak mengenal apalagi menghargai revolusi yang "unik" dilakukan para leluhur kita sendiri. Pendekatan koparatif semacam ini dapat juga kita gunakan dalam pembahas per- bandingan pemerintahan Orde Lama dan Orde Baru (bahkan Orde Revormasi) dalam sejarah lama, bisa kita bandingkan proses masuknya agama-agama di dunia ke Indonesia (Hindhu-Budha, Islam, dan Kristen) masuknya paham-paham ke Indonesia beserta dampaknya, berbagai persamaan dan perbedaan etnis dan budaya etnis kita sendiri yang majemuk.

\section{3) Analisis Tektual (Tekxtual Analysis)}

Menekuni dokumen-dokumen dari sumber-sumber pertama (primary Sources) yang menuliskan dikenal atau tidak dikenal dalam penelitian sejarah sebenarnya, pada hakekatnya untuk mendapatkan dan memahami "makna" (meaning) yang tertulis maupun yang tersirat. Hal ini perlu juga dilatihkan dan diajarkan kepada para anak didik kehendaki mereka tidak harus menjadi sejarawan di kemudian hari. Begitu pula dengan karya-karya sejarah (historiografi) perlu dilihat sebagai teks-teks yang maknanya harus digali, ditafsirkan, dan dipahami maksud teks itu sendiri atau maksud sebenarnya dari penulis-penulisnya (sejarawan) dengan tulisanya itu. Analaisis teks itu harus merupakan bagian dari pembelajaran sejarah di kelas-kelas sejarah. Untuk itu guru-guru sejarah perlu dilengkapi dengan "ilmu bantu" a.l. hermeneutika (hermeneutics) yang pada giliranya dapat tularkan kepada siswa-siswanya dalam memberikan mereka "indar empati", kemampuan menafsirkan dan menjelaskan berbagai fenomena sejarah. (Kneller, 1984: 6598).

Hermeneutika (hermeneutics) semula digunakan untuk penjelasan dan penafsiran Injil kegiatan yang digunakan oleh pendetapendeta dan ahli-ahli agama ketika mereka mengambil satu pasal dari Injil dan mengembangkan apa yang mereka pikirkan maknanya pada waktu itu dituliskan, dan mungkin, apa artinya bagi orang-orang yang 
hidup sekarang. Pada dekade-dekade terbar terutama tahun 1960an istilah hermeneutika diambil oleh para peneliti dalam ilmu-ilmu kemanusia-an (humanities, humaniora), ilmu-ilmu sosial, dan ilmu behavioral (behavioral sciences). (Thomas, 2003: 94).

Wilhelm Dilthey (1833-1911), ahli filsafat yang banyak disebut berjasa dalam meluncurkan gerakan hermeneutika pada masa modern ini, mendefinisikan hermeneutika sebagai "pemahaman fenomena sosial dalam arti motif-motif dari para pelaku/partisipan dan makna-makna (dari motif-motif itu) bagi institusi dan peristiwa". Bubner yang juga dikutip oleh Thomas Menyatakan "bagi ilmu hermeneutika, pemahaman berarti suatu pengertian fundamental tentang kebenaran (trutb) yang ter-jadi dalam proses hubungan inter-subjektif (intersubjective prosses of communication) dan melalui mediasi sejarah" (Thomas,2003: 94).

Jadikan berbagai makna yang dikenakan kepada hermeneutika itu berkisar pada :

(1) Yang sangat terbatas (the very limitet) (seperti memperkirakan motif-motif dalam situasi sosial atau memperkirakan makna yang dimaksud oleh isi dokumen dalam konteks ketika dokumen itu dibuat pertama kali).

(2) Yang sangat luas (the very broad) (keseluruhan seni dan sains interprestasi dengsn segala versinya).

Menurut Thomas, hermeneu-tika itu paling sering digunakan untuk maksud menafsirkan :

(a) Bagaimana konteks asal suatu komunikasi (dokomen, orasi, komentar, gerak isyarat) mempengaruhi makna/ arti komunikasi pada waktu dan tempat itu.

(b) Bagaimana komunikasi yang sama itu harus dipahami sekarang ini. Oleh sebab itu penafsiran kontekstual dapat cocok untuk menjawab berbagai pertanyaan-pertayaan, misalnya :

- Orang/manusia macam apa yang dimaksud dalam Deklarasi Kemerdekaan Amerika denga kata "orang-orang" (men), bahwa "semua manusia/orang diciptakan sama (all men art creaed equal")

- Apa ciri-ciri konteks sosial di India dan dunia Internasional tahun 1940an yang membuat gerakan perlawanan damai, Gandhi berhasil? (Thomas, 2003: 94).

- Dalam konteks politik bagaimana naskah Proklamasi 17 Agustus 1945 diucapkan oleh SukarnoHatta?

Sehubungan dengan diatas tugas-tugas yang harus dilakukan:

(a) Mengumpulkan evidensi tentang artiarti (meanings) kata dan kondisi sosial/politik pada waktu dan tempat dari peristiwa yangdijelaskan.

(b) Menunjukkan bagaimana kon-disikondisi itu serupa dan berbeda dari kondisi sekarang ini.

(c) Menyarankan bagaimana per-samaanpersamaan dan perbeda-an itu dapat mempengaruhi sebaik orang-orang sekarang memahami waktu dahulu dan temapat-tempat yang jauh. (Thomas 2003: 94).

\section{Penutup}

Model-model pendekatan pembelajaran sejarah yang saya bahas di atas bukan satu-satunya panacea (obat mujarab) untuk semua masalah yang dihadapi oleh guru-guru sejarah dalam kelas agar siswasiswa menaruh perhatian kepada pengajaran dan pembelajaran sejarah. Berdasarkan pengalaman mengajar sekian lama, pendekatan-pendekatan di atas saya coba 
tawarkan kepada peserta seminar. Isu kontroversial dapat menyebabkan siswasiswa berpikir dan menghargai perbedaanperbedaan pendapat. Pendekatan histori komparatif dapat memperluas jangkauan dan cakrawala pemahaman siswa-siswa tentang apa yang sudah terjadi dan apa yang sedang dialami atau baru saja dialami di suatu waktu dan temapat tertentu dimuka planet ini. Pendekatan analisis teks mempertajam wawasan siswa tentang makna yang tersurat dan tersirat dalam sebuah gagasan/wacanan yang tertulis pada teks /lisan, dalam konteks waktu dan ruang ketika ia hidup. 


\section{Daftar Pustaka}

Cantor, Norman F. Dan Berner, Samuel, ed. The Modern Era. 1815 to the Present. New York: Thomas Y. Crowell Co. 1971

Clough, Shepard B; Gay, Peter, Warner, Charles K. ; Cammet, John M. The Eropen Past. Reappraisals in History Since Waterloo. 2ed.ed. Volume II. New York : The macmillan Company. 1970

Conkin, Paul dan Stromberg, Roland. The Heritage and the Challenge of History.... New York: Dodd, Mead dan Company. 1971.

Evans, Roland W. Dan Saxe, David Waren. Handbook On Teaching Social Issues. NCSS Bulletin 93. 1996. 130163

Garvey, Brian dan Krug, Mary. Models of History Teaching in the Seecondary School. Oxford University Press. 1997.

Gee, Wilson. Social Sciense Research Methods. New York: AppletonCentury-Croft Inc. 1950

Kneller, George F. Movements of thouht in Modern Education. New York: John Wiley dan Sons. 1984.

Neuman, W. Lawrence Social Research Methods Qualitative and Quantitative Approaches. 4 th. Ed. Boston: Allyn and Bacon. 2000.

Smith, Denis. The Rise of Historical Sociologi. Oxford: Polity Press. 1991.

Stradling, Robert ; Noctor, Michael ; Baines, Bridge. Teaching Controversial Issues. Melbaurne: Edward Arnold, 1985
Thomas, R. Murray. Blending Qualitative dan Quantitative Research Methods in Theses and Dissertations. Thaosand Oaks, California. Corwin Press, Inc. 2003.

(http//www.my-ecoach.com/idtim-eline/ learningtheory.html. Bandung, 19 Maret 2006. 08-02-2004) 